\title{
Use it or lose it: The influence of second order effects of practical components on storing energy harvested by pyroelectric effects
}

\author{
A.E. Beasley ${ }^{1}$, C.R. Bowen ${ }^{2}$, D.A. Zabek ${ }^{2}$ and C.T. Clarke ${ }^{1}$ \\ ${ }^{1}$ Department of Electronic and Electrical Engineering, University of Bath, BA2 7AY, UK \\ ${ }^{2}$ Department of Mechanical Engineering University of Bath, BA2 7AY, UK
}

\begin{abstract}
Harvesting energy using the pyroelectric effect has seen growth as a potential energy source for low power applications, such as self-powered and autonomous wireless sensor networks. The scavenged energy is generally at low power levels, from $\mathrm{mW}$ to less than $\mu \mathrm{W}$. While the voltages generated by pyroelectrics can be appreciable, the electric currents can be low in the order of nano-amps. In the case of pyroelectric harvesting the frequency of operation can also be low, typically much lower than $1 \mathrm{~Hz}$, due to the slow temperature oscillations and transients in systems of large thermal mass. The combination of low power levels and low frequency of operation means that methods of storing electrical energy generated by pyroelectrics and the influence of inherent second order losses is of importance to create efficient harvesting devices. This paper examines the second order characteristic effects of practical capacitors and diodes for storage. The stored energy decay characteristics for commercially available components are examined and the data is used to characterise the second order effects. Selected components are then used in a pyroelectric harvesting system to determine potential improvements by appropriate selection of components with low loss.
\end{abstract}

\section{Index terms: energy-harvesting, energy-storage, pyroelectric}

\section{Introduction}

There is currently significant research effort to consider methods of recovering wasted energy from a variety of sources such as mechanical vibrations, heat and radiation [1-3]. Two such methods currently undergoing development are pyroelectric and piezoelectric energy harvesting which involve the process of recovering energy from temperature changes and mechanical vibration respectively. A major challenge for such systems is the design of methods of conditioning and storing the harvested energy so that it can be efficiently employed in its final application, e.g. as a source of energy for intermittent transmission of data in an autonomous wireless sensor network. The electrical components in harvesting and storage systems will exhibit both first order and second order loss characteristics. The first order losses are operating losses that occur when the device is turned on, such as joule heating and depletion zone losses [4], and these are well known [5]. Second order losses are not normally considered in typical electronics with mains or battery supplies. These are typically losses due to current flowing in the reverse direction when components, such as diodes, are not being driven or the stored charge on a capacitor leaking away over time.

Energy harvesting circuits have the potential to suffer from second order component losses, which can be over-simplified or assumed negligible [6,7,8]. The presence of loss in applications related to pyroelectric harvesting is of particular importance since the harvested energy from the pyroelectric effect is often small (in the $\mu \mathrm{W}$ range) and thermal fluctuations and transients typically occur at low frequency. This paper will examine second order effects in commercially available components and will address the implications of second order effects for harvesting applications. It will be demonstrated that, despite the apparently detrimental first order characteristics of some components, their more beneficial second order characteristics have a greater impact on the low frequency energy harvesting performance.

\subsection{Pyroelectric harvesting}


Under short circuit conditions the harvesting of energy from the pyroelectric effect produces an electric current, proportional to the rate of change in temperature $(d T / d t)$ that the pyroelectric material is subjected to such that:

$$
I=\frac{d Q}{d t}=p A \frac{d T}{d t} \quad \text { (Eqn. 1) }
$$

where $Q$ is the induced pyroelectric charge, $A$ is the electrode surface and $p$ is the pyro-electric coefficient where:

$$
p=\frac{d P_{s}}{d T} \quad \text { (Eqn. 2) }
$$

In this case $P_{\mathrm{s}}$ is the magnitude of the electrical polarisation vector $[9,10]$. When the material is heated under open-circuit conditions, the electric field and resulting potential difference, $\Delta V$, is generated across the two surface electrodes. If the material is assumed to behave as a parallel plate of capacitance $(C)$ then:

$$
C=\frac{A \varepsilon_{33}^{\sigma} \varepsilon_{0}}{h}
$$

where $\varepsilon_{33}^{\sigma}$ is the relative permittivity of the pyroelectric at constant stress and $h$ is the material thickness. Based on the $Q=C U$ relationship between pyroelectric charge $(Q=p A \Delta T)$, capacitance and voltage, the corresponding voltage for an induced change in temperature $\Delta T$ is then defined as:

$$
\Delta U=\frac{p}{\varepsilon_{33}^{\sigma} \varepsilon_{0}} h \Delta T \quad \text { (Eqn. 4) }
$$

Currents in the order of hundreds of nano-amperes have been recorded [9] for pyroelectric harvesting systems. In addition to the low currents, the supply frequency can be low $(<1 \mathrm{~Hz})$ due to the slow temperature oscillations in systems of large thermal mass. As an example, an energy harvesting application has been proposed that uses a piezo-pyroelectric hybrid material placed in pavements to harvest kinetic and thermal energy over a 24 hour period [8]. This combination of low current and frequency for pyroelectric harvesting provides significant challenges for charging an energy storage unit, such as a capacitor or a battery since they suffer from leakage; this includes the loss of charge over time even when electrically unloaded. For piezoelectric vibration harvesting the frequencies of operation can be much higher $(>10 \mathrm{~Hz})$ so that losses are less problematic.

Since silicon based electronics that would be powered this way require low voltage and direct currents, power rectification is required [11]. Unfortunately, charging devices that leak to this extent using a low frequency, low current harvesting signal may result in a significant proportion of the energy that is harvested being lost due to the inherent characteristics of the components. It is also important to note that the capacitors and batteries are not alone in experiencing leakage currents. Components used to convert the signal from AC to DC, for example diodes in a full bridge rectifier, also suffer from reverse leakage current [12] and will cause power loss as voltage is dropped across them in the forward direction.

A commonly used charging circuit for energy harvesting charges a capacitor with four diodes arranged in a full bridge rectifier as in Error! Reference source not found.. The aim of this paper is to study the losses caused by components in a rectification and storage circuit, categorising the cause impact of these losses and finally to determine how best to mitigate them. 


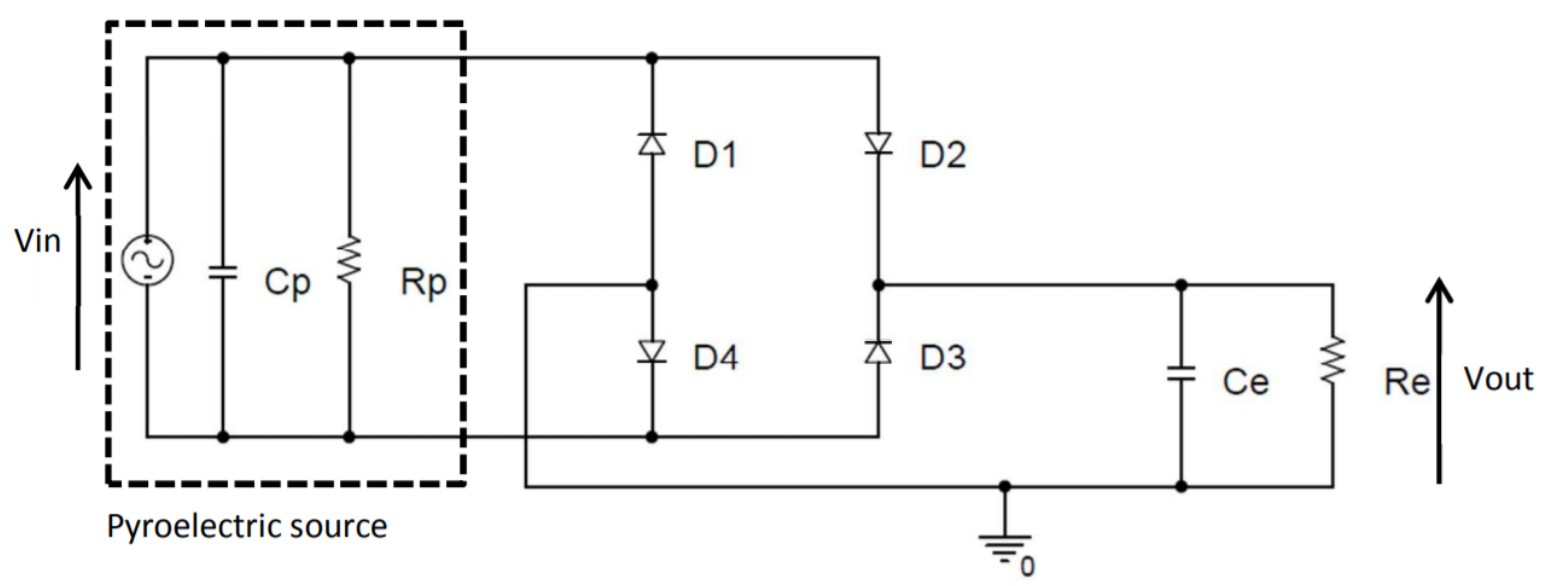

Figure 1. Capacitor charging circuit for harvesting using a full bridge rectifier. $C_{p}$ is source capacitance, $R_{p}$ is source resistance, $C_{e}$ is load capacitance, $R_{e}$ is load resistance, $D 1$ to $D 4$ - full bridge rectifier diodes.

\section{Experimental methods}

Characterisation of commercially available capacitors with a variety of dielectric characteristics (type, capacitance magnitude and rated voltage) was undertaken with and without full bridge rectifiers to record their self-discharge behaviour. An automated system was devised that supplied the component under test with an initial charge of $3 \mathrm{~V}$ for a period of $10 \mathrm{~s}$; this value was selected so as to not saturate the analogue to digital converter. The remaining charge on the component was measured at a sampling frequency of $2 \mathrm{~Hz}$ over a period of $600 \mathrm{~s}$.

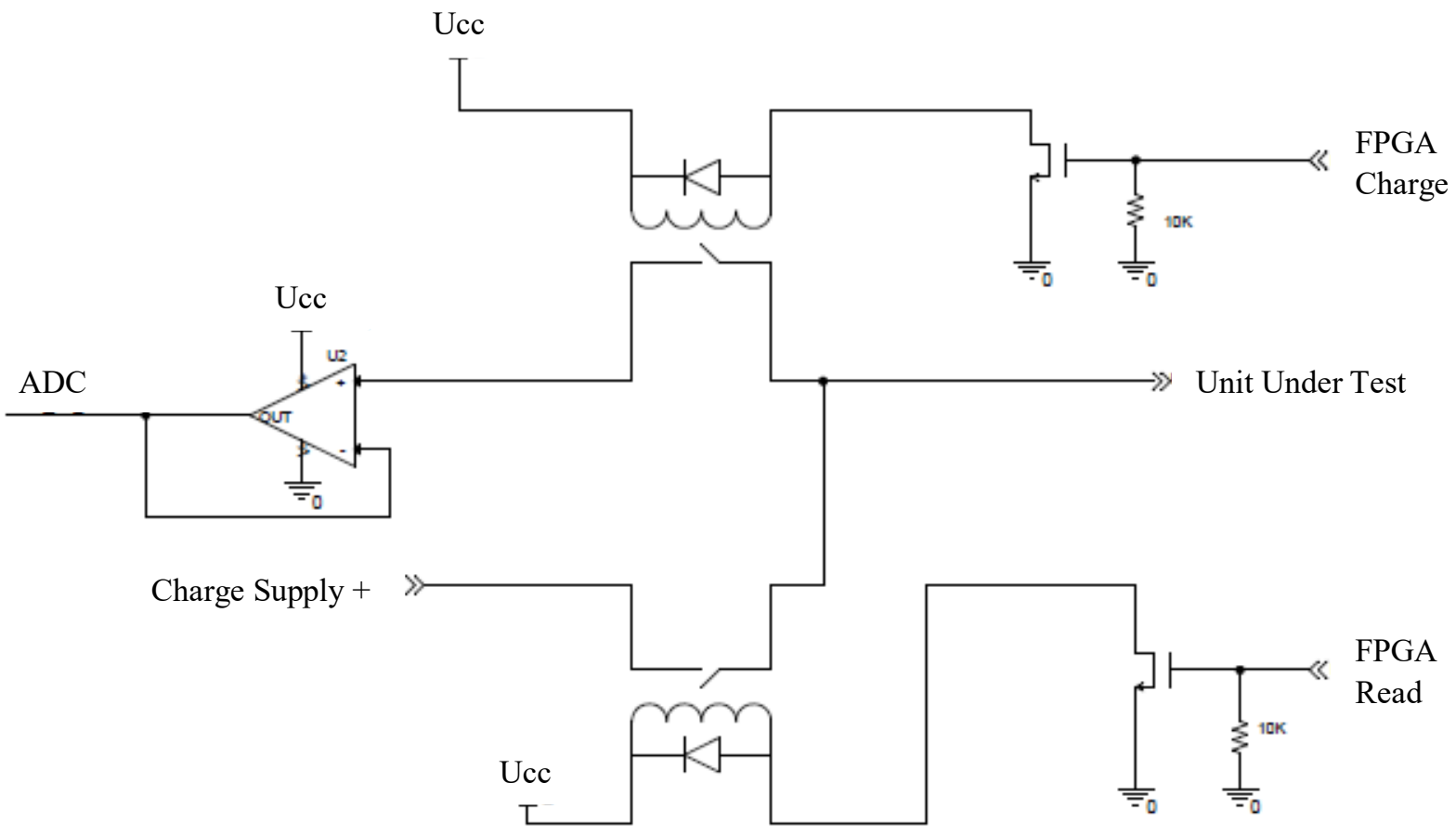

Figure 2. Simplified leakage tester interface circuit. Ucc is the supply voltage. $A D C$ is analogue to digital converter. 
A field programmable gate array (FPGA) was used to interface between the component being tested and a computer. Scripting in Tcl [13] allowed for automated data collection. The data collected was passed to MATLAB for analysis; this provided a discharge curve and the corresponding leakage current. The test circuit is shown in Figure 2 and consisted of two relays, which are controlled by transistors connected to the FPGA. One relay was used to connect the components under test to a charging source to provide the initial charge; the second relay was then used to connect the components under test to a buffering amplifier which was then connected to an analogue to digital converter.

In order to design efficient energy transformation systems and aim for low loss electric storage behaviour, components were characterised and selected with respect to their small transient voltage decay. Those with a slow decay are considered those with lowest losses suitable for a pyroelectric energy harvesting application. To quantify the potential improvements by an appropriate selection of components two energy harvesting storage systems were then constructed employing different components. The diodes where arranged as a bridge rectifier directly connected to a pyroelectric, and the pyroelectric element was thermally exposed to infra-red (IR) radiation to achieve heating from radiation and cooling by convection. The material employed here was a soft lead zirconate titanate (PZT) pyroelectric disc (diameter of $1.5 \mathrm{~mm}$ and thickness $0.2 \mathrm{~mm}$ ), type PIC255 supplied by PI Ceramics (UK), with a pyroelectric coefficient of $550 \mu \mathrm{C} \mathrm{m}^{-2} \mathrm{~K}^{-1}$ and a relative permittivity of 1900 [14] Diodes (D1 to D4 in Figure 1) were of the same type for a given test circuit and comparative testing was achieved by replacing all four diodes with a new type.

\section{Results}

\subsection{Capacitor Characterisation}

There are a wide range of available capacitors from various manufactures which makes comparing individual performances difficult. In order to characterise storage capabilities the voltage-time discharge measurements from a selection of X7R capacitors of $100 \mathrm{nF}$ with voltage ratings that ranged from $6.3 \mathrm{~V}$ to $100 \mathrm{~V}$ were conducted; the exact details of the capacitor are in Appendix I. Figure 3 shows the initial measurements where the capacitor is charged to $3 \mathrm{~V}$ and the decay of voltage recorded over time. It can be seen that as the rated voltage of the capacitors increased, the discharge time tended to increase. For the capacitors with higher rated voltage: 16, 25 and $100 \mathrm{~V}$, the remaining charge after $500 \mathrm{~s}$ is $0.5 \mathrm{~V}$ higher than the $6.3 \mathrm{~V}$ rated capacitor. Thus it can be concluded that charging the capacitors to a lower percentage of their rated voltage provided a slower discharge curve. 


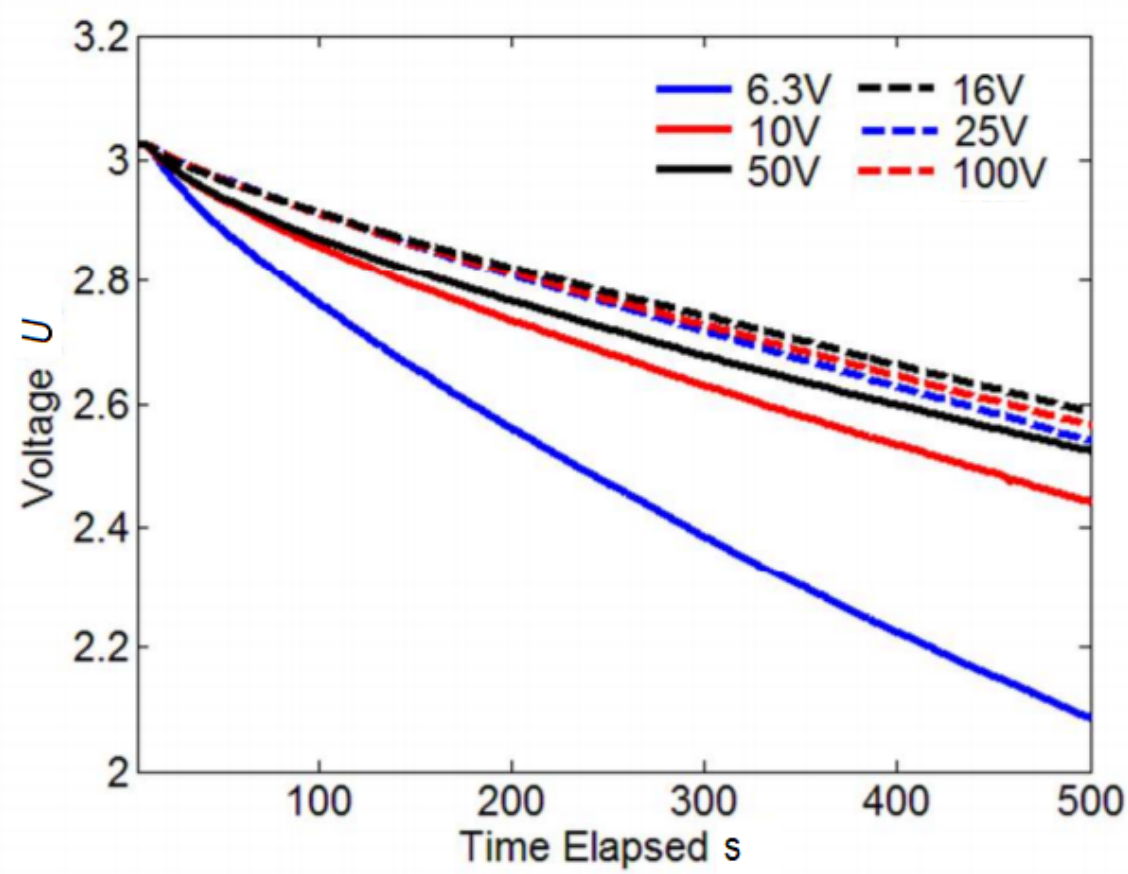

Figure 3. Voltage discharge curves from a range of $100 \mathrm{nF}$ capacitors from various manufacturers (see Appendix I for details of capacitors).

The next stage was to examine the influence of the capacitance. The leakage current of capacitors $\left(I_{\text {Leakage }}\right)$ with a variety of load capacitances $(100 \mathrm{nF}$ to $10 \mathrm{mF})$ were calculated using the one percent change in the voltage level $(\Delta U)$ on the capacitor $(C)$. Figure 4 shows the calculated leakage currents for the various capacitances where it can be seen that an increase in the capacitance tends to increases the leakage current of the capacitive device; precise details of the capacitors are in Appendix II. It can be concluded from Figure 3 and Figure 4 that selecting capacitors with the lowest capacitance and highest rated voltage leads to lower losses. The following section will examine second order losses in the diode components.



Figure 4. Leakage current for different capacitors with different capacitances and dielectric characteristics (see Appendix II for details of capacitors). 


\subsection{Diode Characterisation}

Diodes were compared with respect to their reverse blocking voltage and the range of reverse blocking voltages was $50 \mathrm{~V}$ to $4 \mathrm{kV}$; the exact details of the diodes evaluated are in Appendix III. For diode characterisation, $100 \mathrm{nF}$ capacitors rated at $50 \mathrm{~V}$ were selected and charged to $3 \mathrm{~V}$ since the low capacitance and a high rated voltage component provided the lowest losses.

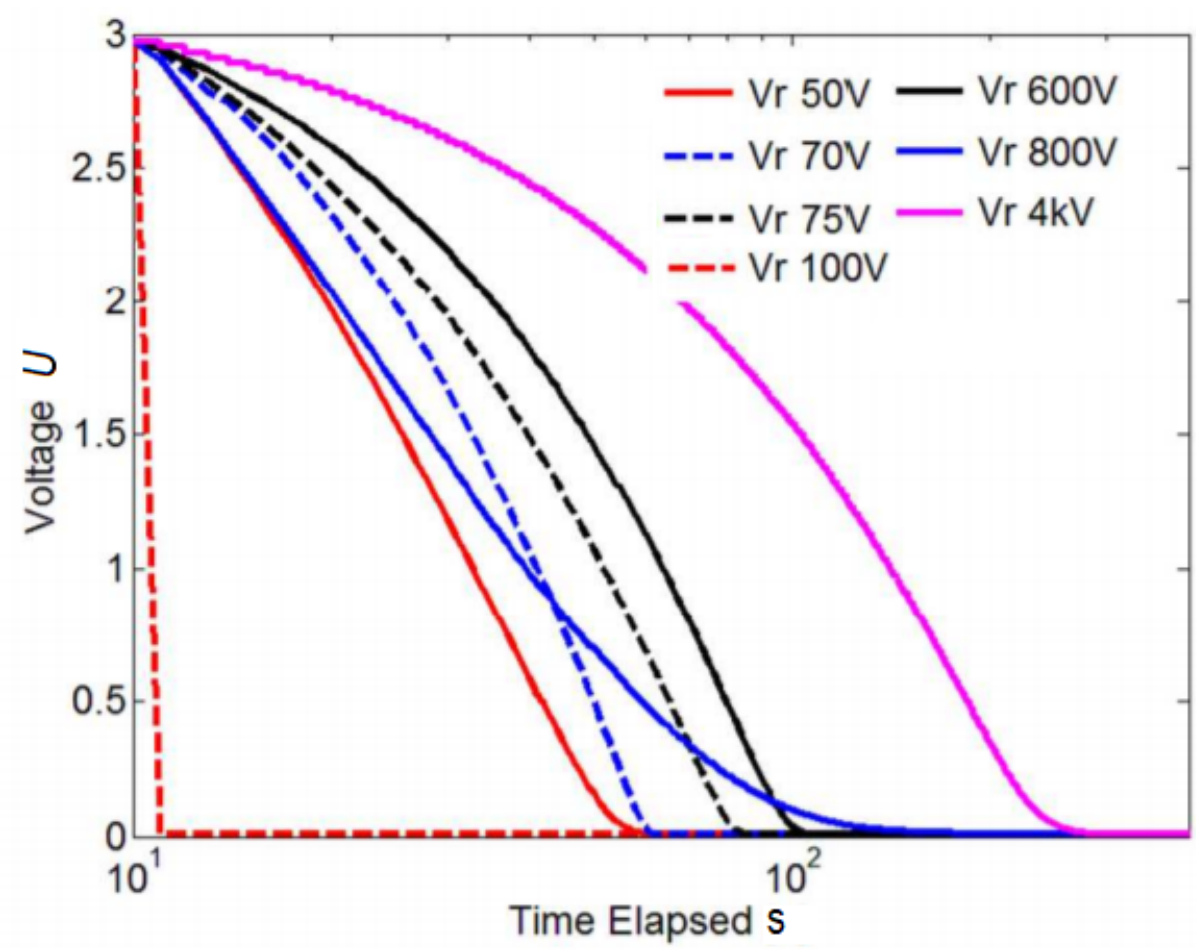

Figure 5. Voltage discharge for a $100 \mathrm{nF}$ and $50 \mathrm{~V}$ rated capacitors with a selection of bridge rectifiers of different reverse blocking voltage, $U_{r}$, (see Appendix III component details).

A variety of diodes were arranged as an h-bridge rectifier, as in Error! Reference source not found., in order to analyse the voltage decay of the capacitor over time due to the leakage current. It is desirable to minimise the resistive loads on the system to minimise leakage current from test equipment. Therefore, the same test set up was used as was used for testing capacitors alone, removing the parasitic effects of an ammeter. Figure 5 shows the voltage decay as a result of reverse leakage current through the diodes in the rectifier. Since the voltage falls to near $0 \mathrm{~V}$ within a timescale of $250 \mathrm{~s}$, unlike when the capacitors tested alone, it is clear that the reverse leakage current losses dominate the system losses for the low capacitance tested $(100 \mathrm{nF}$ rated at $50 \mathrm{~V})$. It also shows that the time taken for the capacitor to discharge and approach $0 \mathrm{~V}$ tends to increase as the reverse voltage of the diode increases. This is apparent in the behaviour of the $100 \mathrm{~V}$ diode (Figure 5), which allows the capacitor to discharge in less than $0.5 \mathrm{~s}$. Standard small signal diodes, such as the those rated to have a reverse voltage of $75 \mathrm{~V}$, also offer poor reverse leakage characteristics since these diodes caused the system to discharge in under $100 \mathrm{~s}$. In contrast, diodes that are rated at $4 \mathrm{kV}$ reverse voltage and have a discharge time of two to three times that of the $75 \mathrm{~V}$ rated diodes.

\subsection{Pyroelectric Energy Harvesting Demonstration}


In order to evaluate how knowledge of the leakage current and discharge of individual component influence the performance of energy harvesting circuits, selected components were evaluated in a pyroelectric energy harvesting system using a full bridge rectifier, as in Figure 1. Tests where performed using a pyroelectric material as the charging source for a $100 \mathrm{nF}$ X7R $50 \mathrm{~V}$ capacitor (low capacitance and high rated voltage), with two different bridge rectifiers with high and low reverse blocking voltages; namely (i) $4 \mathrm{kV}$ rated diodes (GPO2) and (ii) $75 \mathrm{~V}$ rated diodes (IN4148). As shown by Eqn. 3 the voltage produced by a pyroelectric source is proportional to the temperature. To examine the incluence of losses at different operating timescale the heating/cooling frequency for pyroelectric harvesting was swept over three decades $(10 \mathrm{mHz}$ to $10 \mathrm{~Hz})$.

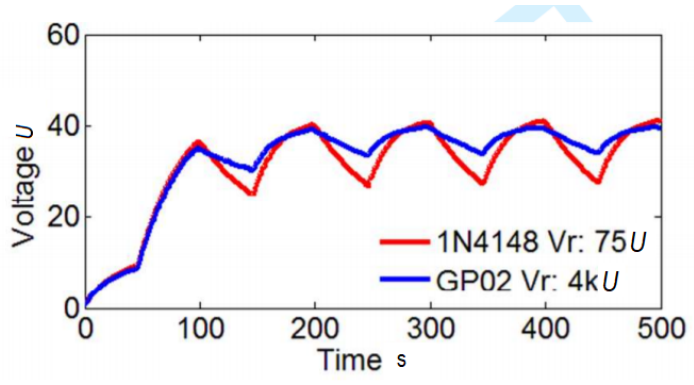

(a)

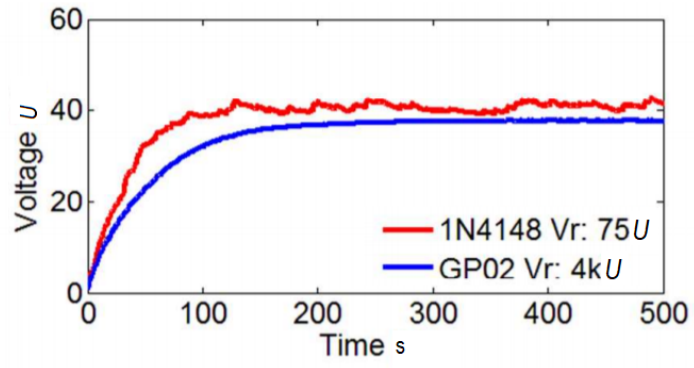

(c)

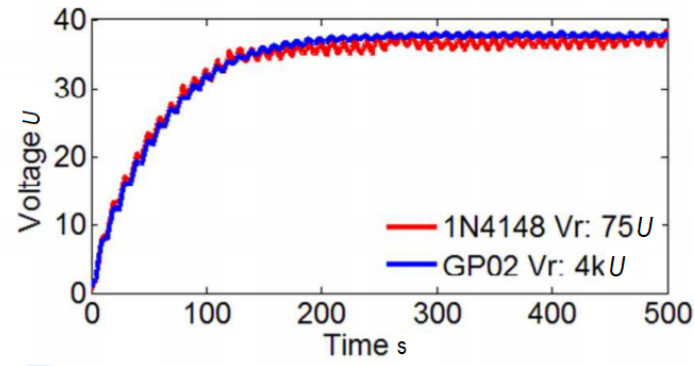

(b)

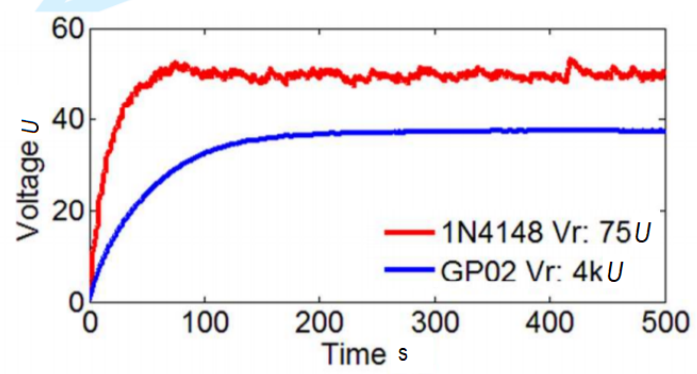

(d)

Figure 6. The voltage on the $100 \mathrm{nF}$ AVX X7R capacitor using $4 \mathrm{kV}$ and $75 \mathrm{~V}$ rated rectifier bridges while being charged from a lead zirconate titante source heated at different frequencies for $500 \mathrm{~s}$. (a) $10 \mathrm{mHz}, 5$ cycles (b) $100 \mathrm{mHz}, 50$ cycles (c) $1 \mathrm{~Hz}, 500$ cycles (d) $10 \mathrm{~Hz}, 5000$ cycles.

Figure 6 shows the voltage on the storage capacitor over a 500s charge period when being charged from a lead zirconate titanate ferroelectric source that is irradiated at four different frequencies: $0.01 \mathrm{~Hz}$ ( 5 cycles $), 0.1$ $\mathrm{Hz}(50$ cycles), $1 \mathrm{~Hz}(500$ cycles) and $10 \mathrm{~Hz}(5000$ cycles). The plots at the higher frequencies of $1 \mathrm{~Hz}$ and $10 \mathrm{~Hz}$, show how the dominating first order effects allow the $75 \mathrm{~V}$ rated diodes to achieve a higher voltage on the sotrage capacitor; this may be the optimum component selection in this frequency range which are particularly important in vibration energy harvesting applications. A characteristic of pyroelectric harvesting is their low frequency of operation and at the lower heating/cooling frequencies $(10 \mathrm{mHz}$ in Figure 6a) there is clearly a large leakage due to second order effects which allow the $4 \mathrm{kV}$ rated rectifier to maintain a higher voltage on the sotrage capacitor.

As a consequence of this different behaviour, the energy stored on the capacitor $1 / 2 \mathrm{CV}^{2}$, for the two rectifier types after five minutes of charging varies for different frequencies. Above $100 \mathrm{mHz}$ the $75 \mathrm{~V}$ diode rectifier performs more efficiently than the $4 \mathrm{kV}$ diode but it is less efficient at the lower frequencies. As the frequency of operation increases the diodes are subject to heating effects, which are likely to impact on performance. It could be expected that the recifier diodes (GP02) would have better performance when operated at higher frequencies as they are designed for higher power applications. As a result of higher currents, higher power applications tend to suffer greater heat dissipation. Including these diodes for comparison agianst small signal diodes indicates there is no benefit from these diodes. The small signal diodes operate more efficiently above $100 \mathrm{mHz}$, indicating that over the tested freqency range, the heating effect could also be favouring the smaller diode. The GP02 rectifier diode has a similar reverse leakage current as the small signal 1N4148. The 90\% discharge time for the two rectifier types at the $10 \mathrm{mHz}$ frequency can be calculated from the gradient of the discharge line in Figure 6 . The 
low voltage $75 \mathrm{~V}$ diode gives a $90 \%$ discharge time of $81 \mathrm{~s}$ whereas the high voltage rectifier has a discharge time of $189 \mathrm{~s}$, giving a better energy retention time.

To distinguish between the first order and second order losses the ratio of the energy stored on the capacitor using the $4 \mathrm{kV}$ diode (GPO2) is divided by the storged energy for the $75 \mathrm{~V}$ diode (1N4148) and the data is presented in Figure 7. The point at which both diodes are equally efficient $(4 \mathrm{kV}$ diode/70 $\mathrm{V}$ diode $=1)$ is approximately $0.2 \mathrm{~Hz}$. Below this frequency the second order effects are dominating and the $4 \mathrm{kV}$ diodes perform better, in terms of energy retention despite their larger losses from the first order effects; for the $4 \mathrm{kV}$ the forward voltage drop max is $3.0 \mathrm{~V}$ while for $75 \mathrm{~V}$ diode the forward voltage drop max is $1.0 \mathrm{~V}$ (Appendix III). Above this frequency the $4 \mathrm{kV}$ diodes would be a poor choice since the first order effects leads to greater loss than the $75 \mathrm{~V}$ diodes. Such an approach allows the selection of approprtiate components based on operation freqeuncy and duration of temperature flucuations.

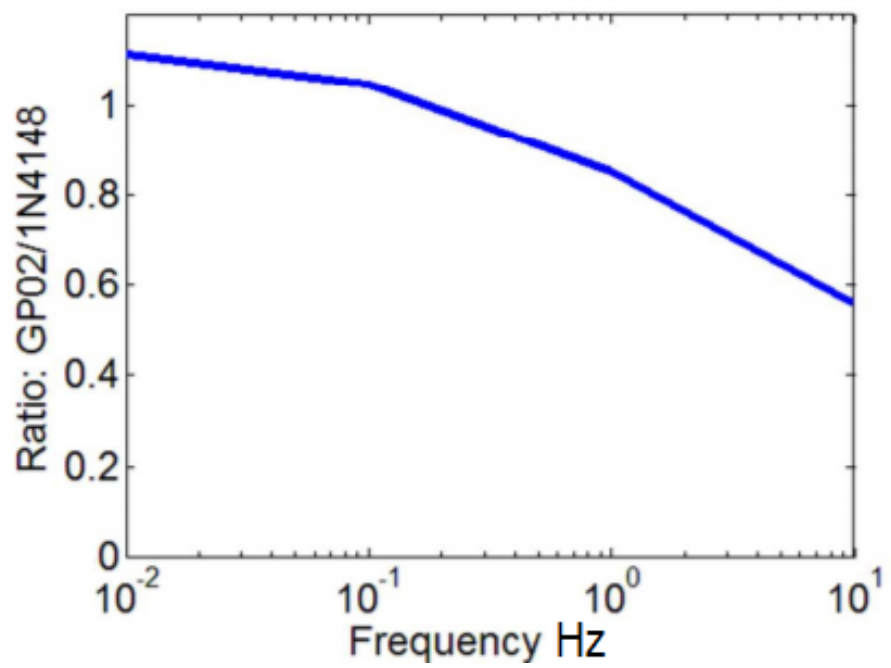

Figure 7. Ratio of the energy stored on the $100 \mathrm{nF} X 7 \mathrm{R} 50 \mathrm{~V}$ capacitor after 5 min charged with a pyroelectric source using two different diode types (CPO2 and 1N4148) in the rectifier.

Assuming that many natural temperature frequencies of oscillation are well below $1 \mathrm{~Hz}$, the high $4 \mathrm{kV}$ blocking voltage rectifier is therefore more suitable for pyroelectric energy harevsting applications due to low second order losses. At $10 \mathrm{mHz}$, the energy stored in the system with the $4 \mathrm{kV}$ rectifier is $0.7 \mu \mathrm{J}$ compared to $0.63 \mu \mathrm{J}$, which is $11.1 \%$ higher and greater benefits are expected at even lower frequencies.

\section{Conclusions}

The choice of the components for both the rectifier and the capacitor in full bridge rectifiers with storage capacitor systems can greatly affect the efficiency of the system, especially for low frequency pyroelectric energy harvesting systems. The leakage current from an unloaded capacitor is dependent on the capacitance and the percentage of the rated voltage of the capacitor being charged. The dielectric characteristic of the capacitor will have some effect on the discharge time, but other factors such as capacitance and rated voltage are more dominant. If the capacitance is relatively low $(\sim 100 \mathrm{nF})$ then the leakage current of the diodes used to form a bridge rectifier can dominate the losses of the system. The leakage current of the diodes is governed by the magnitude of the reverse voltage and the forward current capability. The diodes used in the rectifier should have low forward current and very high reverse voltage capabilities. The lower the frequency of temperature change the more important this consideration becomes due to the dominance of the second order effects; such influence are of particular 
inportant for low frequency pyroelectric harvesting. As an example, an approprate selection of diodes showed than it can lead to a gain of up to $11 \%$ in harvested energy at a frequency of $10 \mathrm{mHz}$.

\section{Acknowledgements}

We acknowledge funding from the European Research Council under the European Union's Seventh Framework Programme (FP/2007-2013) / ERC Grant Agreement no. 320963 on Novel Energy Materials, Engineering Science and Integrated Systems (NEMESIS).

\section{References}

[1] C.R. Bowen, H. Kim, P. Weaver and S. Dunn, Energy \& Enviromental Science, 7, 25 (2014).

[2] G. Sebald, E. Lefeuvre, D. Guyornar, IEEE Transactions on Ultrasonics Ferroelectrics and Frequency Control, 55, 538 (2008)

[3] C.R. Bowen, J. Taylor, E. LeBoulbar, D. Zabek, A. Chauhan, R. Vaish, Energy \& Enviromental Science 7, $3836(2014)$

[4] [2] W. Storr, "PN Junction Theory," 23rd Sept 2014. [Online]. Available: http://www.electronicstutorials.ws/diode/diode_2.html. [Accessed 27th Sept 2014].

[5] T. Avant, J. R. Cruce and G. Park, K. Farinholt, Evaluation of energy harvesting conditioning circuits SPIE Smart Materials \& NDE Symposium, Proc. SPIE, 8343 (2012)

[6] U. Erturun, C. Green, M. L. Richeson and K. Mossi, Journal of Intelligent Material Systems and Structures, $25,1838(2014)$.

[7] J. Lee, K.. Lee, M.K. Gupta, T.Y. Kim, D.Le, J. Oh, C. Ryu, W. J. Yoo, C. Kang, S. Yoon, J.Yoo, S. Kim, Advanced Materials, 26, 765 (2014).

[8] A.K. Batra, S. Bhattacharjee and A. K. Chilvery, "Energy harvesting roads via pyroelectric effect: a possible approach," Proc. of SPIE, 803519 (2011).

[9] A. Cuadras, M. Gasulla and V. Ferrari, Sensors and Actuators A-Physical, 158, 132 (2010).

[10] R.W. Whatmore, Rep. Prog. Phys., 49, 1335 (1986).

[11] R.M. Vullers, R. Van Schaijk, I. Doms, C. Van Hoof and R. Mertens, Solid-State Electronics, 53, 684 (2009).

[12] G.D. Szarka, P.P. Proynov, B.H. Stark, S.G. Burrow, N. McNeill, "Experimental investigation of inductorless, single-stage boost rectification for sub-mW electromagnetic energy harvesters:, International Symposium on Low Power Electronics and Design (ISLPED), pp.360-366, 2011.

[13] Altera, "Tcl Scripting," 3006 2014. [Online]. Available: http://www.altera.co.uk/literature/hb/qts/qts_qii52003.pdf. [Accessed 0209 2014].

[14] PI Piezo Technology, "Piezoelectric Materials," PI Ceramic GmbH, [Online]. Available: http://piceramic.com/products/piezoelectric-materials.html. [Accessed 29th Sept 2014].

Appendix I. X7R capacitors used for results in Figure 3.

\begin{tabular}{|c|c|c|c|c|}
\hline Manufacturer & Product code & $\begin{array}{c}\text { Capacitance } \\
(\mathbf{n F})\end{array}$ & $\begin{array}{c}\text { Rated } \\
\text { voltage (V) }\end{array}$ & $\begin{array}{c}\text { Capacitance } \\
\text { tolerance (\%) }\end{array}$ \\
\hline Johanson Dielectrics & 6R3X14W104MV4T & 100 & 6.3 & \pm 20 \\
\hline
\end{tabular}




\begin{tabular}{|c|c|c|c|c|}
\hline MULTICOMP & MCSH18B104K100CT & 100 & 10 & \pm 10 \\
\hline AVX & 0603YC104K4T2A & 100 & 16 & \pm 10 \\
\hline MULTICOMP & MC0603B104K250CT & 100 & 25 & \pm 10 \\
\hline TDK & CGA3E2X7R1H104K080AA & 100 & 50 & \pm 10 \\
\hline MURATA & GRM188R72A104KA35D & 100 & 100 & \pm 10 \\
\hline
\end{tabular}

Appendix II. Capacitors used to characterise capacitor leakage for different capacitances, Figure 4.

\begin{tabular}{|c|c|c|c|c|c|c|}
\hline Manufacturer & Product code & $\begin{array}{c}\text { Dielectric } \\
\text { characteristic }\end{array}$ & Capacitance & $\begin{array}{l}\text { Rated voltage } \\
\text { (V) }\end{array}$ & $\begin{array}{c}\text { Capacitance } \\
\text { tolerance }(\%)\end{array}$ & $\begin{array}{l}\text { Leakage } \\
\text { current }\end{array}$ \\
\hline AVX & 0603YC104K4T2A & $\mathrm{X} 7 \mathrm{R}$ & $100 \mathrm{nF}$ & 16 & \pm 10 & $47 \mathrm{pA}$ \\
\hline TDK & $\begin{array}{l}\text { C1608X8R1E104K080A } \\
\text { A }\end{array}$ & $\mathrm{X} 8 \mathrm{R}$ & $100 \mathrm{nF}$ & 25 & \pm 10 & $93 \mathrm{pA}$ \\
\hline $\mathrm{AVX}$ & 06035L104K4T2A & $\mathrm{X} 8 \mathrm{~L}$ & $100 \mathrm{nF}$ & 50 & \pm 10 & $38 \mathrm{pA}$ \\
\hline AVX & 06035G104ZAT2A & Y5V & $100 \mathrm{nF}$ & 50 & $+80 /-20$ & $69 \mathrm{pA}$ \\
\hline TDK & $\begin{array}{l}\text { C1608X5R1H104K080A } \\
\text { A }\end{array}$ & $\mathrm{X} 5 \mathrm{R}$ & $100 \mathrm{nF}$ & 50 & \pm 10 & $38 \mathrm{pA}$ \\
\hline TDK & $\begin{array}{c}\text { CGA3E3X7S2A104K080 } \\
\text { AB }\end{array}$ & $\mathrm{X} 7 \mathrm{~S}$ & $100 \mathrm{nF}$ & 100 & \pm 10 & $53 \mathrm{pA}$ \\
\hline MURATA & $\begin{array}{l}\text { GRM188C80E106ME47 } \\
\text { D }\end{array}$ & $\mathrm{X} 6 \mathrm{~S}$ & $20 \mu \mathrm{F}$ & 2.5 & \pm 20 & $2.2 \mathrm{nA}$ \\
\hline TAIYO YUDEN & LMK107BJ106MALTD & $\mathrm{X} 5 \mathrm{R}$ & $10 \mu \mathrm{F}$ & 10 & \pm 20 & $3.4 \mathrm{nA}$ \\
\hline Cellergy & CLC04P010F12 & SUPERCAP & $10 \mathrm{mF}$ & 4.2 & $-20 /+80$ & $6.1 \mu \mathrm{A}$ \\
\hline
\end{tabular}

Appendix III. Diodes used for diode characterisation, Figure 5.

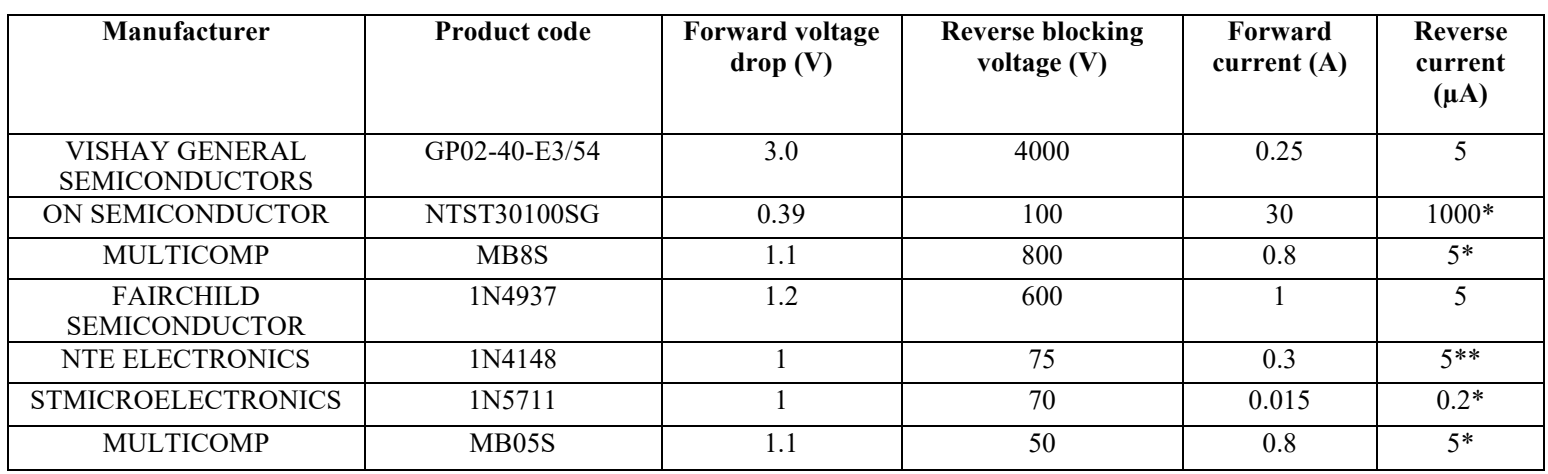

$*$ at $25^{\circ} \mathrm{C}$

** at reverse voltage of $75 \mathrm{~V}$ 